\title{
LAS MURALLAS COMPARTIMENTADAS EN LOS CASTROS DE ASTURIAS: BASES PARA UN DEBATE
}

\author{
POR \\ JORGE CAMINO MAYOR \\ Servicio de Patrimonio Histórico, Consejería de Cultura. Asturias
}

PALABRAS CLAVE: Edad del Hierro. Castros prerromanos. Murallas. Asturias (provincia). Siglos IV-III a.C.

KEY WORDS: Iron Age. Prerroman hillforts. Walls. Oviedo (province). $4^{\text {th }}-3^{\text {rd }}$ centuries B.C.

\section{RESUMEN}

Hace tiempo que en algunos castros de Asturias se reveló la existencia de murallas compartimentadas. Con un planteamiento localista se acuñó la denominación de murallas de módulos y se les asignó un origen autóctono. Más recientemente se ha mantenido su inicio en los siglos vI-v a.C., o incluso antes, basándose en las excavaciones de la Campa Torres y en la cronología pretendida para otros poblados. En este artículo, por contra, se defiende que este tipo de obras forma parte de las conocidas convencionalmente como murallas de cajones, cuya expansión en la Península se produce durante la segunda Edad del Hierro. Paralelamente, los trabajos en castros de la ría de Villaviciosa permiten cuestionar la datación de la muralla de la Campa, se propugna una reinterpretación de su estratigrafía fundacional, a la vez que se aquilatan las referencias de otros castros. Finalmente, se postula que estas murallas deben datarse en Asturias, por ahora, a partir de los siglos IV-III a.C.

\section{SUMMARY}

Some time ago, divided walls were discovered in some Asturian hill forts. Locally, these were called modular walls and were described as local in origin. More recently, they have been dated to the 6 th and 5 th centuries $\mathrm{BC}$ or even earlier, based on the Campa Torres excavations and the proposed chronology for other settlements. This paper, however, maintains that this type of construction forms part of what is conventionally known as drawer walls, which appeared across the Peninsula during the second Iron Age. At the same time, work in hill forts in the ría de Villaviciosa allows the dating of the Campa wall to be questioned, reinterpreting its stratigraphy while evaluating references to other hill forts. Finally, it is suggested that these walls in Asturias should for now be dated at the 4 th and 3rd centuries $\mathrm{BC}$ on.

\section{CASOS Y CARACTERÍSTICAS DE LAS MURALLAS DE MÓDULOS EN ASTURIAS}

Entre los rasgos que presentan las murallas de algunos castros asturianos alcanza especial singularidad el haber sido compartimentadas en segmentos estancos, característica por la que recibieron en la investigación regional la denominación de murallas de módulos. Estos fueron descritos como «sectores o módulos independientes yuxtapuestos unos a otros.
Dichos módulos, cuyos paramentos están muy cuidados y albergan un relleno de mampostería y tierra, presentan forma rectangular de ángulos redondeados y constituyen un alarde poliorcético, puesto que evitan que al derrumbarse una parte de la muralla toda ella quede invalidada» (Maya, 1983: 24).

Esta tipología fortificativa muestra en la región asturiana una sorprendente frecuencia que, curiosamente y contra sus tempraneras menciones, no encontró todavía resonancia en la bibliografía peninsular, donde debe ser encuadrada, a tenor de su coincidencia estructural y siguiendo una nomenclatura al uso en las culturas mediterráneas, entre las llamadas murallas de cajones o compartimentadas (fig. 1).

El reconocimiento inicial de este tipo de murallas se produjo en Asturias, allá por los años 1962 y 63, en el castro de San Chuis - Allande - a raíz de las primeras excavaciones realizadas por F. Jordá. Algunos años después, en 1973, J.M. González anotó en sus diarios la presencia de la misma técnica en el castro de Castillo Veneiro - Tineo-. Ambos casos, que apenas llegaron a ser publicados por sus autores, son recogidos y tipificados por J.L. Maya en sus trabajos compiladores sobre la cultura castreña asturiana (Maya, 1983 y 1988).

En Castillo Veneiro se observan cinco módulos con paramentos de buena fábrica, aprovechándose la junta entre dos de aquellos para la colocación de una atarjea de desagüe (Maya, 1983: 24). Este castro cuenta con un foso y un talud precediendo a la muralla y, pese a que no se conozcan otros materiales que molinos giratorios, debe retenerse su ubicación en las proximidades de importantes explotaciones auríferas de época romana.

A diferencia del anterior, el castro de San Chuis, igualmente provisto de un complejo sistema defensivo de hasta seis fosos y talud y también situado en una comarca de laboreos auríferos, fue objeto de intensas excavaciones. A pesar de haberse finalizado estas en 1986, es muy parco lo publicado al respecto y mayoritariamente obedece a interpretaciones de la documentación original por investigadores ajenos a las excavaciones (Maya, 1983-84 y 1988). Se identificaron 6 ó 7 módulos a lo largo de $76 \mathrm{~m}$ en el recorrido oriental de la muralla, donde, además, se abre 


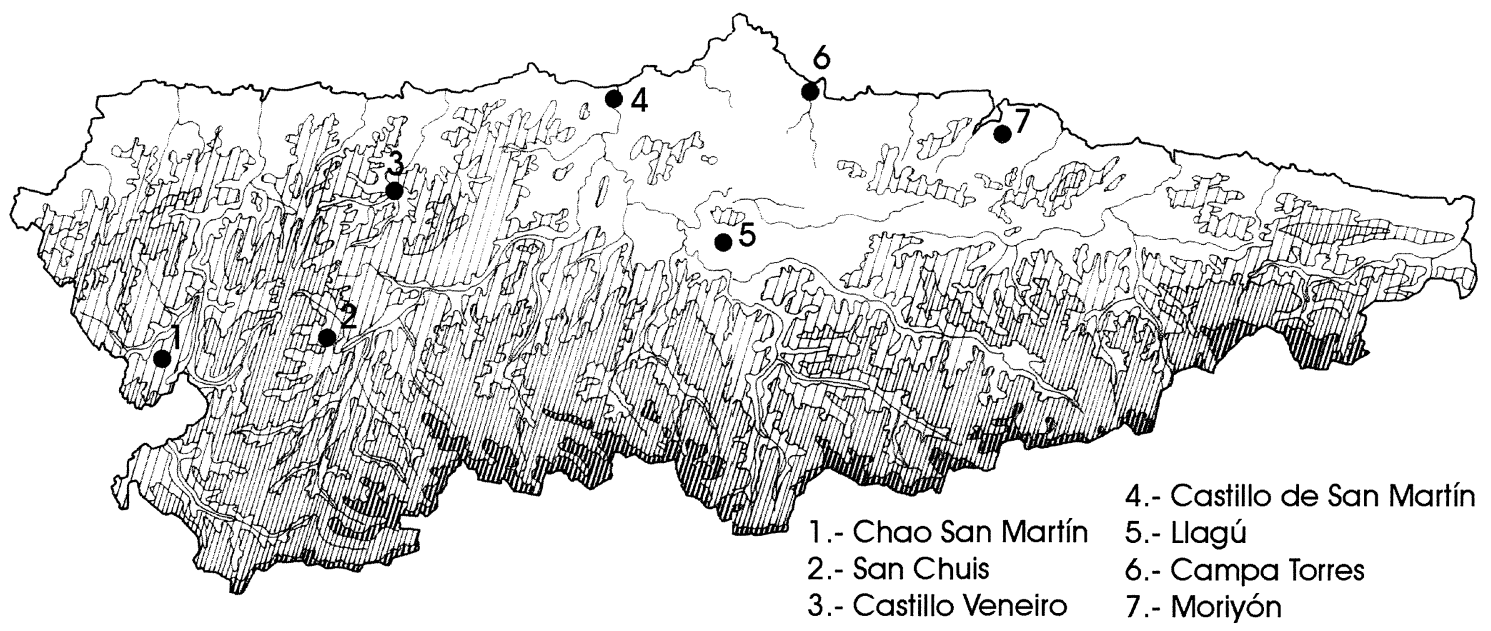

Fig. 1.-Castros asturianos provistos de murallas de módulos.

una puerta probablemente protegida por un muro exterior perpendicular a modo de barbacana. Las divisiones de la muralla no pasaron desapercibidas a su propio excavador, que les aplicó el apelativo de «islas» (Jordá, 1984: 10). En cambio, el lado norte ofrece una muralla lineal. Parecía darse cierto acuerdo en admitir que la trama constructiva - muralla y viviendas de diversa planta- databa del siglo i d.C. en adelante, puesto que «es entonces cuando parece edificarse la muralla e iniciarse el periodo principal de habitación romano» (Maya, 1988: 60) y, aunque se insinuaban atisbos de ocupaciones más antiguas, se partía «del hecho de no haberse podido individualizar ningún nivel estrictamente prerromano» (Maya, 1988: 60). Estos datos se fundaban en las afirmaciones del propio excavador (Jordá, 1984: 10) y en sus perfiles estratigráficos, en los que la muralla, elemento configurador del hábitat, se representa por encima del estrato III adosando a su lienzo interno el estrato II con materiales romanos (Maya, 1988: fig. 17A). Últimamente se han publicado diversas dataciones que pueden indicar la ocupación del lugar desde tiempos muy antiguos: UBAR-351, 2600 \pm 60 , 845-530 cal BC; UBAR-218, 2360 $\pm 60,760-205 \mathrm{cal}$ $\mathrm{BC}$; lo que ha dado pie a la defensa de una datación entre los siglos vI-IV para la fábrica de la muralla en un evidente paralelismo con la de la Campa Torres (Cuesta, Jordá, Maya y Mestres, 1996: 232 y 233).

En los últimos años el aumento de excavaciones científicas o por razones de urgencia ha provocado un sustancial incremento de la información concerniente a las murallas de módulos.

El castro más investigado es, sin duda, la Campa Torres - Gijón-, donde se ha exhumado la casi totalidad del conjunto defensivo dispuesto en forma de cortina frontal en un característico emplazamiento en península (fig. 2). Todo el sistema fortificativo responde a un diseño complejo formado por una primera hilera integrada por un profundo foso y un parapeto revestido de un paramento de módulos en su cara posterior. Es, no obstante, la muralla principal la que recaba mayor interés. No es una obra enteramente rectilínea puesto que, además de arquearse ligeramente en una adaptación a la topografía, presenta hacia su lado occidental, coincidente con la zona más elevada, un giro de $90^{\circ}$ para adelantar un tramo que recobra la dirección general de la pantalla (Maya y Cuesta, 1992b: 43-44). La interpretación del mismo como un bastión sería acorde con la existencia de una entrada en el costado occidental, como propugnan los investigadores, pudiendo agregarse que de ese modo y atendiendo a postulados poliorcéticos se presiona sobre el flanco desguarnecido del asaltante. El patio interno a que da lugar la inflexión de la muralla es ocupado por una plataforma de rellenos provista de escaleras de acceso que es interpretada como un paseo de ronda, la cual prosigue un tanto hacia el este ciñendo a la muralla. Finalmente, en el extremo oriental, antes de la desaparición de la muralla provocada por una antigua cantera, presenta otro módulo yuxtapuesto paralelamente al exterior que fue interpretado como barbacana o bastión adelantado (Maya y Cuesta, 1992b: 44). Con independencia de su papel de refuerzo en una zona de mayor desnivel, realmente este baluarte en unión al anterior permitirían batir lateralmente la integridad del pie de muralla, desvelando un sofisticado diseño defensivo. En total son seis módulos de muy diversa longitud y anchura, a veces entre 6,5 y 10 metros de ancho, levantados con lienzos de mampostería de cuarcita armoricana en los que tan sólo se práctico una talla centrípeta regularizadora de la cara vista (Ibidem). 


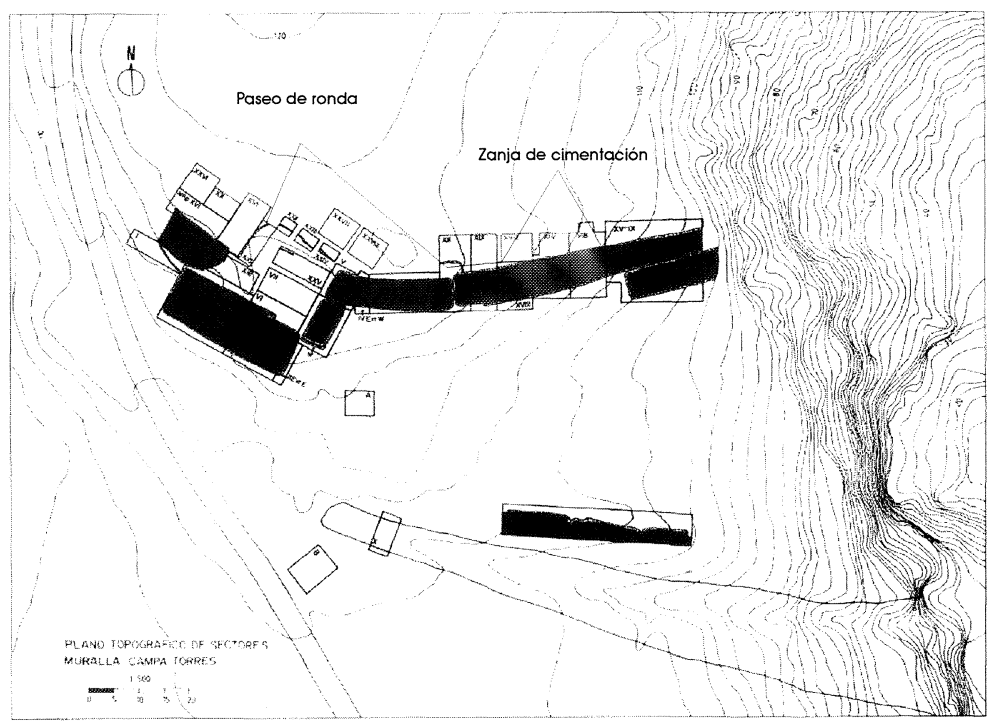

Fig. 2.- «Zona de defensas de Campa Torres» (a partir de Maya y Cuesta, 1995). Las murallas se representan en trama oscura con los sectores de excavación.

La relación contextual para datar el conjunto de la obra se efectúa con el estrato o capa VII, el cual adosa a la base de la muralla, constituida en su mitad occidental por una banqueta fundacional conformada por un relleno de grava gruesa y gravilla de cantos rodados ceñido por un bordillo (Maya y Cuesta, 1995: 112). De ese nivel se obtuvieron varias fechas radiactivas: UBAR-321, 2460 $\pm 50,764-409$ cal BC (Maya y Cuesta, 1995: 109); UBAR-508, 2445+40, $762-404 \mathrm{cal}$ BC; UBAR-509, 2535 $\pm 45,802-517 \mathrm{cal}$ BC; UBAR-514, 2490 $\pm 40,781-419$ cal BC; UBAR$518,2480 \pm 40,769-417$ cal BC; pudiendo incluirse la del estrato $\mathrm{V}$ infrayacente al paseo de ronda, UBAR507, 2555 \pm 45 , cal BC 806-528 (Maya y Cuesta, 1999: 131). A la hora de hacer la transposición de este conjunto de fechas a la fundación de la muralla se opta por su concreción a finales del siglo vı o principios del v a.C., en función de las características del depósito material, entre el que se anota una fíbula de doble resorte, planchas de calderos remachadas, un brazalete tipo La Majúa, pasadores en T, cerámicas incisas en espiga, etc. (Maya y Cuesta, 1995: 112113; Maya y Cuesta, 1999: 133).

Entre los años 1987 y 1996 se desarrolló una investigación en varios castros emplazados en los márgenes de la ría de Villaviciosa, que trató de establecer una secuencia cronológica y cultural de este tipo de poblados cercanos al confín oriental de su distribución en la región (Camino, 1992; 1995a y 1999). Destacaremos aquí únicamente dos aspectos que creemos dotados de mayor relieve para el propósito que nos ocupa. De una parte, la definición de una primera o inicial Edad del Hierro en los poblados de Camoca y Olivar con cinco dataciones en el intervalo de los siglos VIII-VI cal BC y una cultura material pareja. Ambos cuentan con notables barreras defensivas fundamentadas en la formación de taludes de relleno que se acompañan de empalizada, murallas toscas y algún pequeño foso. En un momento simultáneo, o casi, los dos padecen un despoblamiento y no alcanzan la segunda Edad del Hierro (Camino, 1999: 158-159).

De otra parte, los trabajos de excavación se centraron principalmente en el castro de Moriyón, cerro destacado sobre la ría, que presenta una doble ocupación y un disperso epígono, si bien el poblado principal claudica en torno al cambio de era. La primera fase esta indicada por una base sedimentaria en el sector meridional que alberga cerámicas parangonables a las de la primera Edad del Hierro junto a otras atribuibles al comienzo de la segunda Edad del Hierro, pudiendo corresponder a una ocupación inicial de este último periodo o a varias ocupaciones mezcladas por la nivelación. A pesar de excavarse el borde actual del asentamiento no se reconoció ninguna estructura defensiva. El estrato basal, U.E. 54, cuenta con una datación radiactiva enmarcable en un primer momento de la segunda Edad del Hierro: CSIC875, 2320 \pm 45 , cal BC 410-240 (Camino, 1999: 159).

Sobre esa capa se construyó una muralla, soporte estructural de la segunda fase de habitación, que rodea la cumbre en un circuito cercano a $500 \mathrm{~m}$ de longitud, y en la que se han reconocido tres módulos que probablemente sean más dada la reducida superficie 


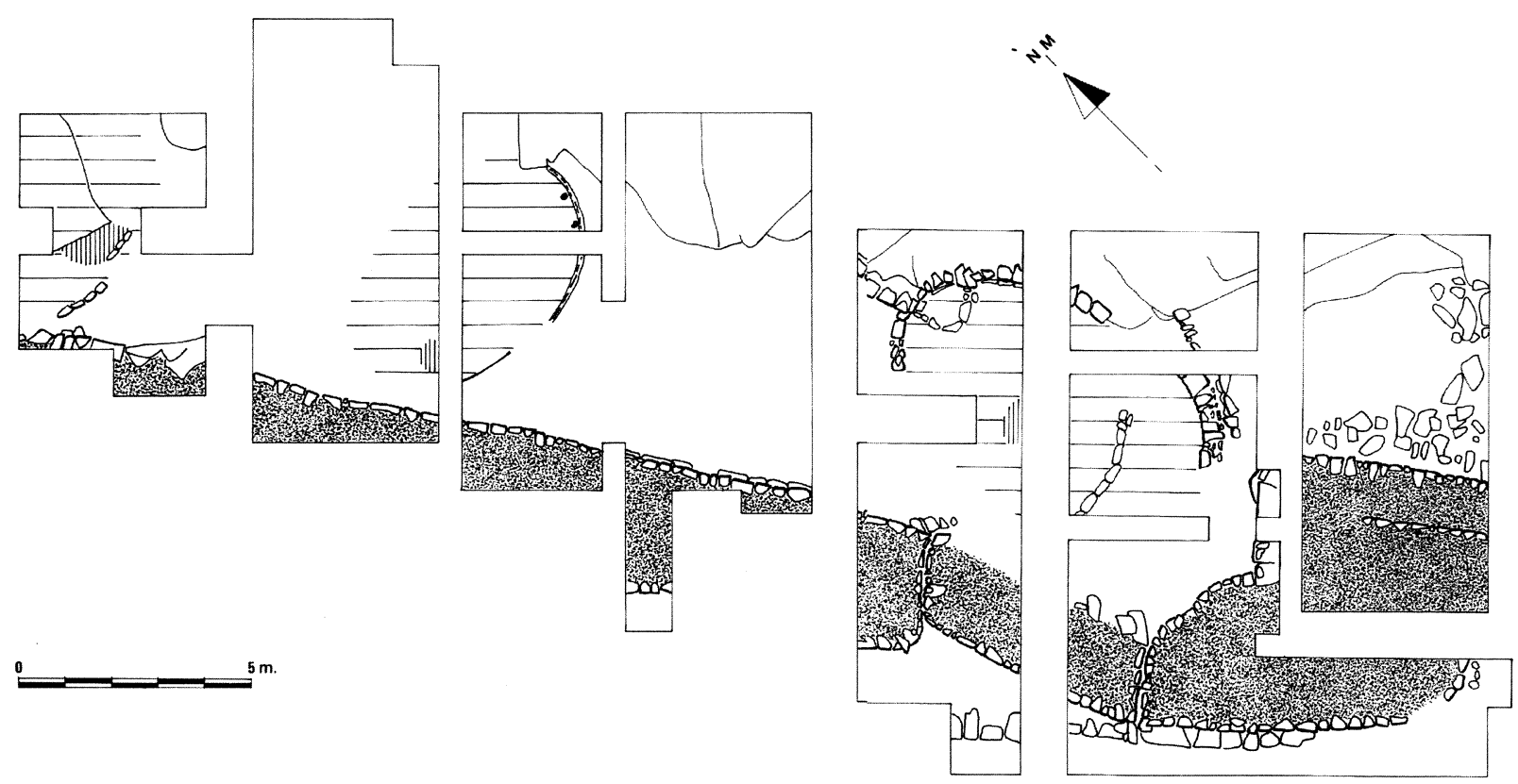

Fig. 3.-Planta del sector D de Moriyón con la muralla en sombreado y las construcciones en rayado.

excavada de la misma — poco más de $40 \mathrm{~m}$ (fig. 3)—. De un nivel con mucho cascote acostado hacia la base del lienzo interno de la muralla y rematado en un enlosado - a todas luces un relleno que brinda servicio de caminería al pie de aquella-, que constituye la mejor deposición asociada a la fundación de la muralla, se obtuvo otra datación radiocarbónica correspondiente a la segunda Edad del Hierro y coherente con la fecha del nivel precedente: CSIC-874,

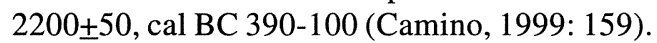

Otras fechas teóricamente relacionables con la construcción de la muralla, que luego se traerán a colación, subrayan el contexto fundacional durante la segunda Edad del Hierro, caso de CSIC-873, $2280 \pm 50$, cal BC $400-190$ y CSIC $-876,2100 \pm 60$, cal BC 210-30 AD (Camino, 1999: 159-160).

La técnica de módulos también aparece en el castro de Llagú, en las inmediaciones de Oviedo. Sometido en los años 1995 y 1996 a una excavación de urgencia bajo la dirección de los arqueólogos J. Ruibal y $\mathbf{M}^{\mathrm{a}}$.L. González, cuyo polémico desenlace está aún pendiente, lo acogemos aquí a través de la publicación de un lote de dataciones en una serie divulgativa (Maya y Mestres, 1998), utilizando únicamente los escuetos datos publicados. Los trabajos de excavación abarcaron unos $5.000 \mathrm{~m}^{2}$, casi una tercera parte del poblado, coincidiendo con el sector más fértil. El castro contiene dos grandes fases de ocupación y parece que la muralla, muy transformada en época altoimperial, dispuso del sistema de módulos en ambas. La ocupación inicial está enmar- cada por un buen número de fechas radiactivas, de las que, salvo dos de ellas, UBAR-493, 2380 \pm 48 , 558-369 cal BC al 78,24\% y UBAR-495 2380 \pm 50 , 593-581 - seguramente 593-381 - cal BC al $75,95 \%$, cuya calibración a dos sigmas se dispara hacia los siglos VI-V a.C., siete dataciones convergen en los siglos IV-III a.C. (Maya y Mestres, 1998: 9). En función de ello se defiende que las muestras más antiguas «marcarían preferentemente el inicio del poblado en el siglo v cal a.C. o, como muy tarde, a comienzos del siglo IV» (Ibidem: 10).

Como consecuencia de una excavación de urgencia en el Castillo de San Martín, histórica fortificación medieval ribereña de la desembocadura del Nalón, se desveló una muralla de módulos asentada sobre cabañas de la segunda Edad del Hierro (Carrocera y Camino, 1996: lám. 1) que se encuentra en estudio por E. Carrocera.

Finalmente, las excavaciones en curso en el castro del Chao Samartín, en el confín occidental de la región, han deparado igualmente una muralla de módulos asignada a la segunda Edad del Hierro con la datación CSIC-1158, cal BC 350-110, y sellada por la evolución urbanística de época romana (Villa, 1999: 119-120).

\section{RAZONES DE UN DEBATE CRONOLÓGICO}

A pesar de la amplitud y calidad de la información examinada, lejos de producirse una coinciden- 


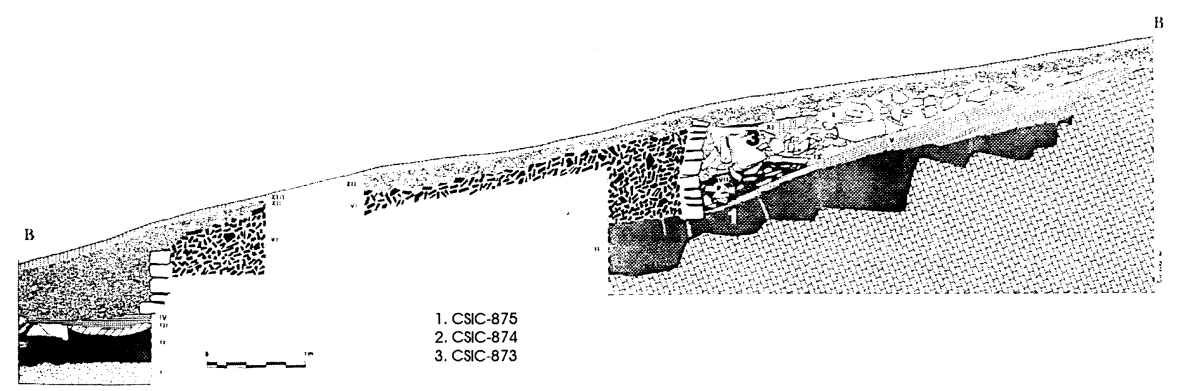

Fig. 4.-Perfil B-B' del sector D de Moriyón con proyección de las muestras datadas.

cia de posturas que contribuya a precisar la cronología inicial de las murallas de módulos, las opiniones se han polarizado en sendas interpretaciones contrapuestas, básicamente sustentadas en los dos poblados por el momento provistos de mayor volumen de datos concernientes a este tema, esto es, los castros de la Campa Torres y Moriyón. Y ello contra la uniformidad técnica de estas obras y en oposición a la proximidad geográfica y similitud cultural de los asentamientos. Como se vio, en el primero se viene propugnando la existencia de la muralla desde el primer momento de ocupación, con una cronología del siglo vi o principios del v a.C. una vez matizadas las dataciones absolutas con la colección arqueológica. Para el segundo se ha tendido a centrar la muralla en el siglo III a.C. Por otra parte, no es superfluo agregar que los espectros cronológicos de las dataciones radiactivas para la fundación de ambas murallas son desde un enfoque estadístico irreconciliables, ya que la primera se fecha a dos sigmas en 769-409 cal B.C. - basada en UBAR-321, pero que debiera conjugarse con las demás dataciones equivalentes-, en tanto que la segunda se mueve entre $380-180$ cal B.C. En suma, bajo los criterios cronológico y cultural la muralla de la Campa se situaría en el horizonte de la primera Edad del Hierro, mientras que la de Moriyón pertenece plenamente a la segunda.

Para solventar esas discrepancias se han intentado varias salidas. Por parte de los investigadores del castro gijonés se ha pretendido buscar el respaldo en el envejecimiento de las murallas de módulos de otros castros, al tiempo que se sembraba un halo de descrédito de la secuencia cronoestratigráfica de Moriyón. Por mi parte he defendido la posibilidad de que la muralla de la Campa pudiera ser mucho más moderna (Camino, 1995b: 211).

Dentro de este proceso, de las dataciones del castro de Moriyón se ha hecho una valoración carente del contexto arqueológico que condujo a comentarios tales como: «De todos modos, del análisis realizado, se deduce que buena parte de ellas entran abiertamente en contradicción entre sí, lo cual puede estar relacionado con la compleja problemática de su posición estratigráfica poco clara» (Cuesta, Jordá, Maya y Mestres, 1997: 266). No vamos a detenernos en una prolija explicación de las disparidades suscitadas por algunas fechas de Moriyón, en esencia CSIC-849 y CSIC-873. Respecto a la primera, que pretendía datar la ocupación infrayacente a la muralla y cuyo resultado fue 1-250 cal $\mathrm{AD}$, pudiera muy bien obedecer a una infiltración contaminante motivada por las sacas de piedra que afectaron a la muralla y su relleno (Camino y Viniegra, 1999: 246), según se muestra en un perfil simplificado (Camino, 1996: fig. 1A). No vale la pena insistir en esta datación dado su contraste con la evolución del yacimiento, a no ser para entrar en pormenores de la estratificación que poco contribuyen al tema que se trata.

La segunda, que proviene del derrumbe de la muralla, al ser más vieja que la vinculada a la fundación, es lógico que despierte una inevitable desconfianza y merecería un análisis más detallado que el del objeto de este trabajo. Con todo, resulta desconcertante la debilidad reflexiva con que fue valorada, como si sólo se pretendiera desacreditar la secuencia del poblado (Cuesta, Jordá, Maya y Mestres, 1997: 247, 256, 258, 266 y 267). ¿Acaso no será probable que esos carbones inmersos en la maraña del derrumbe de la muralla pertenezcan a un material viejo incorporado al relleno de ella? Si así fuese, aunque la posición se ubique en el derrumbe, su datación, como es comprensible, no indica este postrero episodio, sino el de la erección de la muralla o incluso pudiera ser un material residual de un momento más antiguo (fig. 4). Para evitar el prejuicio de considerar esta fecha un terminus post quem en vez de simul quem con la muralla de Moriyón se integrará entre aquellas susceptibles de asociarse a la fundación de la obra defensiva.

- Así, con la finalidad de estrechar el amplio intervalo de la datación asociada a la fundación de la 


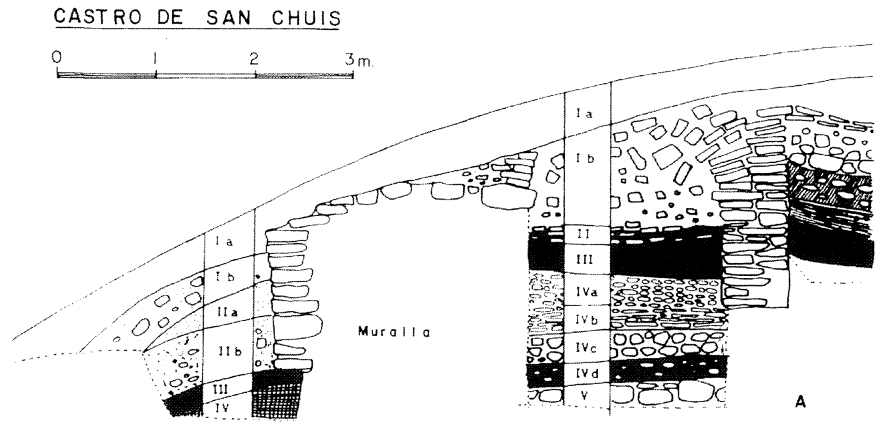

Fig. 5.-Sección N-S desde el exterior de la muralla hasta el interior de la casa I. Excavaciones de F. Jordá en 1962 y 1963 (Maya, 1988). muralla CSIC-874 — cal BC 390-100-, se ha conjugado con las muestras CSIC-873 — la ubicada en el derrumbe de la muralla pero procedente indiscutiblemente de su relleno- y CSIC-876 — vinculada al maderamen estructural de la pared de la cabaña n. ${ }^{\circ} 2$ erigida acto seguido a la muralla- en un test de similaridad. Cabe alegar que la muestra de la cabaña pudiera estar muy rejuvenecida en caso de que se hubiese producido una reparación de la misma, evento no constatado, pero desde un punto de vista teórico esa distorsión queda neutralizada si se considera que la muestra del derrumbe, al ser ligeramente más vieja que la fundacional, pudiera pertenecer a un material viejo escombrado entre el relleno. El resultado de la combinación estadística fue $2203 \pm 30 \mathrm{BP}$, cal BC 380-180, que es el margen en que debió ser construida la muralla. Ahora bien, si se tiene en cuenta que el estrato previo a la muralla aportó una datación cuya máxima vejez no desborda el 400 a.C. y que debe de dotársele de una franja cronológica a lo largo del siglo Iv, acreditada por la presencia de cerámicas propias de la segunda Edad del Hierro, lógicamente en detrimento de la construcción de la muralla en el tramo alto de su intervalo, ies entonces descabellado que defendamos la datación de la muralla de Moriyón en el siglo III a.C.? (Camino, 1995a: 124; Carrocera y Camino, 1996: 58; Camino, 1999: 159-160).

Una de las novedades más sorprendentes reside en la modificación de la cronología del castro de San Chuis, sobre todo en lo que toca a su muralla, y sin embarazo de los primitivos planteamientos estratigráficos se llega a afirmar que «la muralla, aunque nunca ha sido publicada como tal, suele considerarse romana por sus características técnicas (sic), pero hoy esta clasificación no es segura...» (Cuesta, Jordá, Maya y Mestres, 1996: 232). Frente a las conclusiones fundamentadas en la estratigrafía y en el repertorio material, se oponen ahora las dos datacio- nes radiactivas antes citadas - UBAR$351,2600 \pm 60,845-530$ cal BC y UBAR$218,2360 \pm 60,760-205$ cal BC- con el fin de propugnar una datación de la muralla entre los siglos VI-IV a.C. en un inesperado paralelismo con la muralla de la Campa. Basta fijarse en la procedencia de las muestras para percibir el sentido estrictamente cabalístico de las argumentaciones: de la primera se carece de relación contextual con la muralla y del nivel que se extrajo la segunda - yacente sobre la roca, con «cerámicas poco significativas» y en «contacto lateral con la cimentación de la muralla»- se vacila sobre si «fue seguido de una muralla indígena entre los siglos IIII que cortaba los niveles de esa fecha,...fue cortado por una muralla romana», o si se acumuló de forma primaria o secundaria junto a ella (Cuesta, Jordá, Maya y Mestres, 1996: 232 y 233). Por otra parte, no debe perderse de vista no sólo el excesivo intervalo cronológico de la fecha obtenida tras su calibración, una banda de más de 500 años que le otorga una escasa utilidad, sino también, para el tema que nos ocupa, que más del $25 \%$ de su secuencia concierne a los siglos IV y III a.C.

Respecto al castro de Llagú, con un conjunto de siete dataciones convergentes en los siglos IV-III a.C., parece innecesariamente forzado postular una fundación anterior para la muralla a partir de dos dataciones más antiguas (Maya y Mestres, 1998: 10), sobre todo si se repara en que el intervalo de ambas incluye el comienzo del siglo iv a.C. y que una de ellas proviene del espacio externo a la muralla, por consiguiente, fuera del recinto de ocupación. En una fábrica de la muralla en la segunda Edad del Hierro abunda la datación de la muestra 1 de las excavaciones posteriores, 2160 +38 , cal BC 359-63 (López, Álvarez y López, 1999: 244), aunque no proceda de la base del nivel. Otras dos muestras depararon $2414 \pm 41$, cal BC 761-393 y $2355 \pm 44$, cal BC 536-252, pero carecen de relación directa con la muralla, derivándose de todo ello la dificultad de elevar la datación de la misma por encima del siglo IV a.C. (Ibidem: 249).

Como se habrá observado, el intento de envejecer substancialmente las murallas de módulos en los casos anteriores, como el de pretender emparejarlas con las fechas defendidas para la de Campa Torres, tienen muy poca solidez. ¿Qué ocurriría si invirtiéramos la dialéctica y sometiéramos a examen la cronología vehementemente asignada a la muralla del castro gijonés? ¿Pudiera ser que el nudo gordiano de todo este conflicto resida en la interpretación rea- 
lizada hasta ahora en la propia Campa Torres? No puede ocultarse, en efecto, que diversos investigadores han recelado de muchos de los resultados de este castro. Ya en el Congreso Peninsular de Oporto de 1994 se advirtió que las cerámicas de atribución soteña pretendidamente identificadas en el poblado (Maya, 1988) nada tenían que ver con ese horizonte cultural y que la sedimentación intramuros pudiera obedecer a una deposición secundaria, al tiempo que se denunciaba las graves repercusiones para la interpretación del yacimiento de la excavación de la muralla mediante una zanja paralela (Carrocera, 1994: 215). En los últimos años se ha dudado no sólo de la edad de la muralla, sino también de la valoración sostenida para la ocupación antigua del yacimiento y de la cronología atribuida a diversos materiales (Fernández-Posse, 1998: 217). Finalmente $\mathrm{y}$ aunque tenga una relación tangencial con el estudio de la muralla, no deben omitirse las atinadas reservas expresadas a la ocupación prerromana de la gran explanada situada detrás del cerro en el que se encuentra la muralla - lugar que da origen al topónimo la Campa-, lo que obligaría a modificar drásticamente la secuencia y características del poblado que, de este modo, en la época prerromana quedaría reducido al típico promontorio castreño (Orejas y Sánchez-Palencia, 1999: 31-32).

Hoy en día, después de las últimas publicaciones de la Campa (Maya y Cuesta, 1999), resulta más fácil realizar una crítica profunda de la interpretación del yacimiento ya que los contraargumentos que pueden emplearse son, por desgracia, numerosos. Nos limitaremos ahora a analizar el ámbito estratigráfico ligado a la fundación de la muralla de una manera algo más pormenorizada a como lo hicimos hace poco en otro trabajo (Camino, 2000).

Es interesante reparar con cierto detalle en la descripción del estrato VII - no olvidemos, el asociado a la fundación de la muralla, que se fecha en el siglo VI o inicios del v a.C. a partir de las dataciones radiactivas precisadas con la cultura material-, y proceder a su contrastación con los perfiles estratigráficos representados (Maya y Cuesta, 1995: 109112 en especial y fig. 4 y 6). Así, sobre el sector XVIII (fig. 6), situado hacia el lado oriental de la muralla, se relata lo siguiente: «Sobre el suelo rocoso natural se aprecia una capa carbonosa de base, que ha de corresponder al incendio del bosque del siglo XI a.C. Encima se construyó la muralla, utilizándose para su fundamentación una sólida banqueta en forma de plataforma de piedras ceñida por un bordillo, complementada por un relleno de grava gruesa y gravilla de cantos rodados de tamaño medio y sobre la cual se depositó una capa de grandes

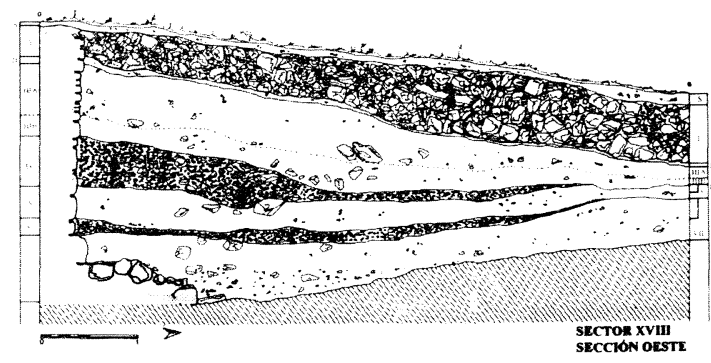

Fig. 6.-Sector XVIII de la Campa Torres. «Corte estratigráfico Norte-Sur, perpendicular a la muralla y apoyándose en ella» (Maya y Cuesta, 1995).

bloques de cuarcita. Como consecuencia de tal estructura, en la estratigrafía perpendicular a la muralla pueden diferenciarse dos zonas distintas, la de fundación de la muralla y la externa a los fundamentos. Sin embargo ambas zonas están homogeneizadas estratigráficamente con una capa negra superpuesta, el denominado $2^{\circ}$ nivel de cenizas», provisto de abundante material antrópico (Maya y Cuesta, 1995: 109 y fig. 4). En el análisis del sector XII-XIX, localizado unos pocos metros más hacia el oeste, se formula una descripción parecida del estrato VII, el cual integra la banqueta y, sobre ella, la muralla, y más al interior el segundo nivel de cenizas (Ibidem: 112). A continuación, sin salir del epígrafe dedicado al estrato VII, se agrega: «El resto de la cuadrícula es una masa compacta de cenizas y gravas angulosas, que contactan con el anterior estrato arenoso, siendo su interpretación más difícil, ya que si bien estamos a gran profundidad y sobre el segundo nivel de cenizas, el material que se halla parece bastante más moderno que él...», y se prosigue después indicando que contacta «en algunos puntos con el suelo natural», para concluir que «por su material y posición inferior al kalathos, este paquete estratigráfico V-VI (además el kalathos se recuperó en el estrato V), así como su enlace con el VII, puede situarse entre el siglo III y primera mitad del II a.C.» (Maya y Cuesta, 1995: 111-112 y fig. 6).

Gran trabajo cuesta descifrar todo el texto precedente y compaginarlo con las ilustraciones de los perfiles de referencia. En primer lugar se aprecia que el nivel de incendio datado en torno al siglo XI a.C. - GrN-18059 y GrN-10060 - no aparece reflejado en los dibujos en su posición por debajo de la muralla, ya que ésta con su banqueta apoya directamente sobre la roca — de hecho, bajo ella se emplea el mismo código gráfico que en el sector XX para indicar la roca (Maya y Cuesta, 1992a: fig. 2)—. Por otra parte, resulta de difícil entendimiento el sentido uniformizador del denominado segundo nivel de cenizas, en realidad el estrato VII, y no diga- 


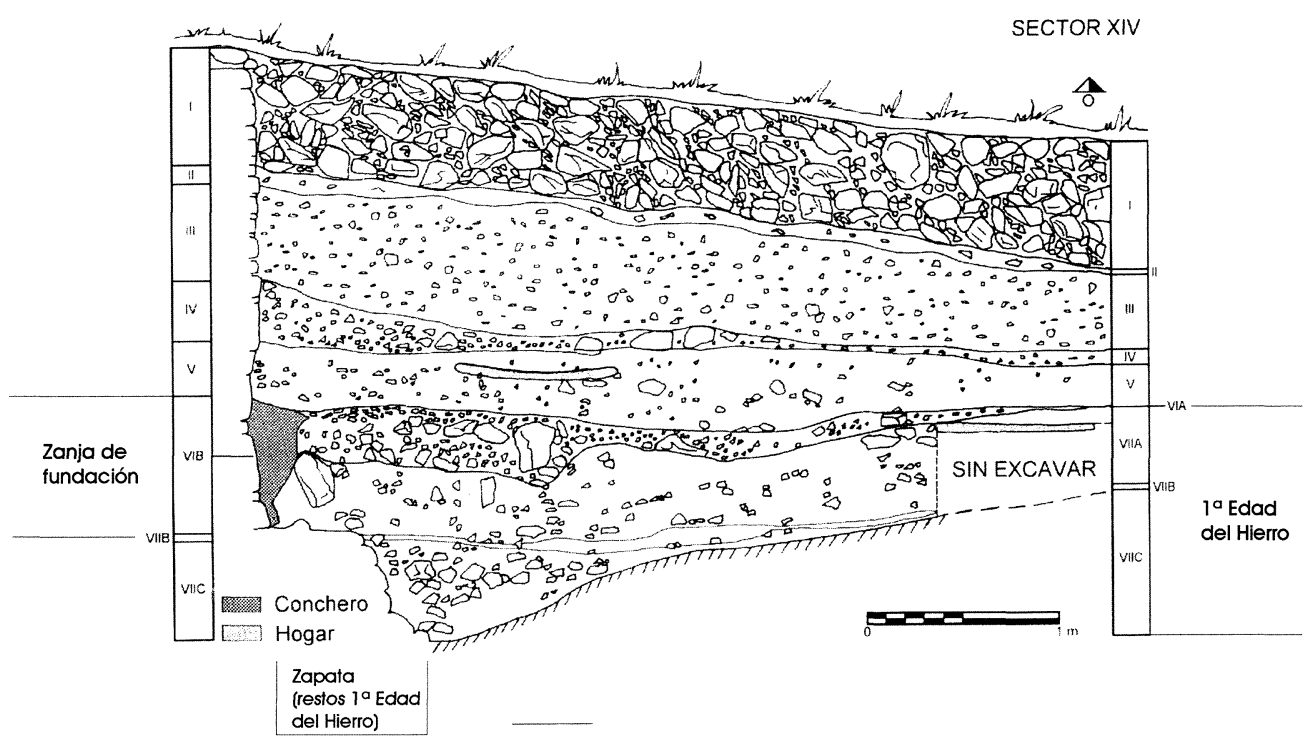

Fig. 7.-Reinterpretación de la estratigrafía del sector XIV de la Campa Torres (a partir de Maya y Cuesta, 1999 , con anotaciones externas del autor).

mos nada de la intromisión del citado paquete V-VI y la zona de enlace con él que se traen a colación en el último párrafo.

Aparte de estas contradicciones, el hasta ahora rutinario estrato VII es objeto de notables modificaciones en la más reciente publicación (Maya y Cuesta, 1999). En la secuencia del sector XIV (fig. 7) el citado estrato VII se trastoca - extrañamente dada su contigüidad al sector XVIII- en una compartimentación de tres subniveles de disposición horizontal y apoyados en la banqueta fundacional de la muralla, dos de ellos interpretados como rellenos y el intermedio como «una línea fina y horizontal» (Ibidem: 127). En primer término llama la atención que, pese a las diferencias existentes con otros sectores, se mantenga la misma nomenclatura para todo el estrato. Sin embargo, la novedad más llamativa es la alusión a que «pegado a la muralla es frecuente la aparición de restos de conchero, que parece corresponder a un material externo a las viviendas, arrojado como basura. Estas conchas se rastrean desde el sector XVIII al VIII a alturas muy distintas, siguiendo la pendiente natural del terreno» (Ibidem: 127). La interpretación de este conchero, denominado capa VIB, es tremendamente esclarecedora en el dibujo del perfil donde, sombreado, se observa adosado a la cara interna de la muralla para descender en forma de cuña por debajo de la capa $\mathrm{V}$, interrumpiendo la conexión de las capas VIA y VIIA con dicho lienzo, hasta llegar al techo de la denominada banqueta fundacional, y quedar por encima de las capas B y C del estrato VII (Ibidem: fig. 1).
En realidad, la silueta en sección del citado conchero es contraria a las leyes de la deposición estratigráfica, salvo que se admita que se trata de una bolsada invasora que corta las capas VIA y VIIA, las cuales se trazan inequívocamente truncadas en su progresión hacia la muralla. No creo que la composición del perfil estratigráfico ofrezca grandes dudas para todo aquel mínimamente versado en las formaciones relacionadas con la cimentación de construcciones, puesto que la bolsada del conchero concuerda perfectamente con el relleno de una convencional zanja de fundación que recorre buena parte de la base interna de la muralla. Luego, dado que la misma afecta a la zona basal de la muralla hasta encabalgarse sobre la denominada banqueta, propongo que la erección de la muralla de módulos del castro de la Campa Torres nada tiene que ver con esa banqueta fundacional ni, por ende, con el estrato o capa VII. En el dibujo del perfil las primeras hiladas de la muralla insertas en la fosa muestran, además, el tosco repié de muchas cimentaciones (fig. 7).

Pero la disociación entre la muralla y lo que se defiende como su zapata no se limita exclusivamente a esta trascendente ruptura estratigráfica, ya que en varias fotografías publicadas (Maya y Cuesta, 1995: fig. 7; Id. 1999: lám. III) puede verse también una separación física que impide toda relación funcional entre ambas (Camino, 2000: 8-10).

$\mathrm{Si}$ la muralla no tiene relación constructiva con la banqueta de bordillo y relleno - forma de cimentación que siempre tuve por bastante insólita-, ni 
con su consiguiente capa VII, ¿en qué momento se construyó? Con las lecturas estratigráficas presentadas no es posible responder de forma taxativa e incluso cabe preguntarse si algún día se podrá hacer. En la sección (Maya y Cuesta, 1999: fig. 1. Fig. 7), por atenernos al examen de la misma secuencia, queda patente que el techo del «conchero» llega hasta la base de la capa $\mathrm{V}$, habiéndose practicado la zanja, en consecuencia, antes de la formación de aquella. Como este nivel cuenta con una cronología de los siglos II-I a.C. (Ibidem: 127), la fundación de la muralla correspondería al inicio de este periodo, lo que sería avalado por el hecho de que la capa VIB constituye la cimentación de una cabaña situada en el nivel superior - algo que viene a confirmar, como era de esperar, la reurbanización interna a que da lugar la construcción de la muralla-. No obstante, de la lectura del texto surge un matiz que contradice el perfil estratigráfico expuesto en aquella figura. Se alude, así, a que «en el extremo occidental, (el del perfil representado) bajo el estrato VI o fundamentación de la cabaña del II a.C., se aprecia una capa de resina que recubre una cabaña con un hogar decorado en el centro...», esta construcción «rompió incluso la zapata fundacional de la muralla y se apoyó casi sobre la roca de base, por lo que ha hecho desaparecer buena parte del $2^{\circ}$ nivel de cenizas» (Maya y Cuesta, 1999: 127). Esta cabaña inferior se supone de los siglos IV-III a.C. sólo porque está bajo la del siglo II a.C. (Ibidem: 127). El problema estriba en que nada de todo esto se refleja en la estratigrafía, a no ser un hogar, dispuesto sobre una banqueta con rótulo indicador de que es una zona sin excavar, que aparece suspendido e imbricado en el estrato VIIA (fig. 7).

Con la reinterpretación única del perfil del sector XIV, tal como se acaba de proponer, nada se opondría, en consecuencia, a aceptar la construcción de la muralla de módulos de la Campa Torres en un momento temprano del siglo II a.C., pero es indispensable apreciar el conjunto de la documentación proveniente de los sectores excavados a lo largo de la muralla. En este sentido, parece acertado subrayar la función del denominado paseo de ronda, una gran estructura formada por material de relleno que se yuxtapone a la cara interna de la muralla en todo su tramo central - sectores XXVI-XIX - y que es considerado bastante posterior a ella (Maya y Cuesta, 1995: 113). No se dispone de mucha información sobre esta obra, pero no sería de extrañar su contemporaneidad a la muralla no sólo por lógicas funciones de refuerzo, nivelación y acceso, sino porque en caso contrario el bastión occidental aparecería desligado del resto de la muralla. No hay seguridad en su datación dentro de un amplio periodo entre los siglos V-III a.C. (Maya y Cuesta, 1995: 113), sin embargo, acto seguido la plataforma de ronda se pone en relación con rellenos y terraplenes de la zona oriental que actúan de consolidación de la muralla y en los que se detectan materiales de los siglos III-II a.C. (Ibidem: 113). Estos materiales deberían suponer un terminus post quem de los siglos III-II a.C. para toda la reforma interior, fecha parangonable a la que defendemos para la fundación de la muralla. Ambos eventos, paseo de ronda y muralla, parecen converger, por tanto, para formar parte de una obra única en un mismo momento.

Concluyamos, pues, con la interpretación de que la ocupación prerromana de la Campa Torres se divide en dos grandes fases, una atribuible a la primera Edad del Hierro relacionada con la denominada banqueta, previsiblemente el residuo de un viejo elemento defensivo, y la otra correspondiente a la segunda Edad del Hierro, quizá del siglo III o principios del ir a.C., responsable de la muralla de módulos y probablemente de los otros complementos defensivos.

\section{LAS MURALLAS DE CAJONES EN EL CONTEXTO PENINSULAR}

Desde un primer momento se consideró que las murallas de módulos asturianas constituían un sistema defensivo novedoso al desconocerse la existencia de paralelos peninsulares (Maya, 1983: 24). Algo más tarde, el mismo autor, tras asegurar la datación prerromana de estas murallas, basándose en Campa Torres, recalca la autoctonía de las mismas (Maya, 1988: 299), a la par que se apunta un paralelismo con los castros abulenses donde se citan muros internos que impiden el demoronamiento de la obra (Maya, 1989: 35). A pesar de la analogía en la finalidad, por el momento y a falta de mayor información, no parece que este parentesco pueda seguir manteniéndose, ya que los muros internos de esos castros meseteños son en realidad paralelos a los lienzos estructurales, respondiendo a la clasificación de paramentos múltiples de otras zonas peninsulares y quizá evocadores de los murus duplex ya descritos por César en las Galias. De hecho la fuente utilizada de referencia muestra rotundamente algo más adelante lo aventurado de esta comparación: «Tampoco sabemos a ciencia cierta si los paramentos internos estarían articulados con los externos mediante tirantes transversales, como se ha dicho alguna vez» (Martín Valls, 1985: 109-110).

En la actualidad la presencia de estas murallas 
en Asturias desde tiempos prerromanos está suficientemente acreditada, y bajo este enfoque indigenista y cronológico cabe admitir la pretendida autoctonía de las mismas. Sin embargo, no parece ésta su mejor calificación a poco que se considere su coincidencia formal y conceptual con las denominadas murallas de cajones, tal como se recogía al principio de este artículo y ya se defendió con anterioridad (Camino y Viniegra, 1999: 244-245). Ciertamente, a tenor de las descripciones literales y de varias ilustraciones, pudiera establecerse alguna diferencia entre las murallas de cajones y las de módulos asturianas. La misma residiría en que las compartimentaciones de las primeras suelen materializarse por medio de muros de una sola hoja designados en ocasiones tirantes, que unas veces adosan sencillamente a los lienzos principales y otras intestan en ellos; mientras en las otras cada cubo cierra independientemente sobre sí de modo que son dos los muros que atraviesan la fábrica de parte a parte en cada junta, como ocurre en Moriyón, Campa Torres, Castillo Veneiro y San Chuis. Soy del parecer de que dicha distinción es meramente formal y que lo verdaderamente trascendente son sus coincidencias estructural y funcional. Con esta noción podría aceptarse otra modalidad más de partición, que estaría representada por la yuxtaposición de módulos en los que los cierres intermedios se integran en cada segmento precedente, ejemplo que se observa en el Chao Samartín (Villa, 1999: 119). Otras variantes menos conocidas consisten en interrumpir los muros divisorios alternativamente desde los paramentos externo e interno, o también, en murallas estrechas, en la introducción de largos bloques a tizón hasta alcanzar el lienzo contrario (Adam, 1982: 32).

El estudio constructivo de uno de los módulos del castro de Moriyón puede servir para vanalizar un tanto las rígidas clasificaciones morfológicas que puedan establecerse en las modalidades de compartimentación. Allí, el cajón aparece definido en toda su integridad en la cara externa de la muralla que apoya sobre la roca, pero el lienzo de la cara intramuros al arrancar de una cota más alta monta sobre la base del relleno que es encofrado por aquel muro exterior. Quiere ello decir que la parte inferior del módulo ha de extinguirse entre el relleno interno, disimulándose en el frente interior con la formación del cajón por encima del terreno.

Las murallas de cajones o de muros transversales son conocidas en el Próximo Oriente desde tiempos muy antiguos, $c a$. siglo IX a.C. El sistema fue empleado por fenicios y griegos de la época arcaica - por ejemplo en Corinto-, pero su proliferación sistemática corresponde al periodo helenístico, y así se registra en Paestum, Nápoles, Sunion, etc. (Winter, 1971; Lawrence, 1979). No está de más agregar que en Europa continental es conocida otra técnica de obras de cajones conseguida por apilamiento de vigas de madera en el interior de la muralla, la cual se designa tipo Kastenbau. El ejemplo más próximo se identificó en Indre - Francia- y por su datación calcolítica se interpreta como un prototipo sin continuidad (Audouze y Buchsenschutz, 1989: 114). La impronta mediterránea de esta modalidad de obra y su éxito quedan de manifiesto en que el propio Vitrubio (I, V, trad. de A. Blánquez) disertase sobre ella, recomendando que, una vez construidos los cimientos de la muralla, «se alzaran otros que vayan del muro exterior al muro interior, y dispuestos en forma de peine, o como dientes de una sierra y con las puntas hacia fuera», evitándose de ese modo que el peso del terreno, por estar repartido en tramos, reviente la estructura de la muralla.

En la investigación peninsular se debe a P. Moret la tipificación de esta técnica poliorcética y un primer repertorio de los lugares en que aparece (Moret, 1991 y 1996). En un breve repaso de los ejemplos de murallas de cajones conocidos en la Península, cabe consignar varios focos o concentraciones regionales. Pero, como podrá colegirse, son contados los casos en que se precisa con elocuencia su existencia.

En el Mediodía peninsular, aunque se suelen citar las murallas de los enclaves con clara repercusión colonial del Castillo de Doña Blanca -Cádiz - y Malaka entre las de tipología de cajones, parece que las dos obras sucesivas del primero han de encuadrarse entre las de casamatas (Ruiz, 1986), $\mathrm{y}$ en el segundo la reducida superficie excavada impide asegurar la división en cajones (Recio, 1988). En cambio, sí se acreditan en Silla del Moro - Ronda-, cuya muralla, que cuenta además con torreones, se articula en casetones rellenos de piedra y tierra, datándose en el ibérico antiguo - siglos VI-V a.C. (Aguayo et al., 1990: 249)—.

La vía hacia el interior peninsular pudiera estar indicada por la fortificación del Cerro de la Plaza de Armas de Puente Tablas - Jaén-, fechada en el siglo VII a.C., donde «se observan diferentes manos que construyeron, a modo de cajones, distintos paños del mismo, de tal modo que son observables hoy las uniones por líneas que en ocasiones permiten distinguir, incluso, procedencias distintas de los materiales» (Ruiz, Molinos y Choclán, 1991: 115116). Si bien luego se añade que en la estructura interna no se observa «por el momento nada que indique un entramado de pasantes que implique una 
infraestructura interna, ello quizás porque sobre la superficie hoy se documenta una reestructuración tardía del siglo III a.N.E.»(Ibidem).

En el Cerro de las Cabezas —Ciudad Real-, uno de los primeros lugares en que se detectó el sistema de cajones, la muralla, de 4 a $5 \mathrm{~m}$ de grosor, se compartimenta a distancias regulares por muros divisorios de $0,40 \mathrm{~m}$ de anchura, rellenándose los espacios intermedios con cascote y tierra. Los trabajos iniciales correlacionaron la muralla perimetral de cajas con la fase B ibérica del poblado, iniciada en el siglo $v$ a.C. y desarrollada principalmente en el IV. Una muralla intermedia que deslinda la acrópolis es datada en la segunda mitad del siglo iv a.C. En todo caso, se defiende la influencia colonial en la complejidad defensiva representada por varias murallas y torres o bastiones (Vélez y Pérez, 1987).

Sin grandes precisiones, cabe la posibilidad de mencionar en el mundo ibérico del norte del país valenciano otras obras por su aparente concomitancia con la técnica que nos ocupa. Se cita, así, un tipo de talud formado por rellenos en el que sobresalen «en toda su anchura diversas hiladas transversales de muretes..., dispuestos aisladamente o a intervalos regulares paralelos, distanciados entre sí de 2 a 4 metros... y cuya finalidad sería la distribución por tramos, del reparto de la carga» (Gusi, Díaz y Oliver, 1991: 88). Dicha obra se encuentra en algunos poblados entre los siglos VI-II a.C. y se supone su origen, a tenor de su rusticidad, en tradiciones locales (Ibidem). Si la descripción no esconde una realidad distinta, pudiera también estar compartimentada la defensa de El Charpolar - Margarida, Alicante-, poblado del Ibérico medio a época republicana, en el que se mencionan unos cercos concéntricos enlazados mediante tabiques perpendiculares (Llobregat, 1972: 51 y 176).

El Castellet de Banyoles - Tarragona - fue considerado un ejemplo arquetípico de las murallas de cajones en la Península, aunque se han efectuado varias objeciones acerca de su verdadera naturaleza - endeblez del muro exterior, que se enlosase la base de los cajones para el relleno y la escasa longitud del tramo en que aparecen- (Moret, 1996: 83-84). Sus investigadores señalaron un sofisticado diseño defensivo que incorpora una muralla en cuyo basamento «se colocaba la tapia encofrada sobre los cimientos de cada paramento, uniéndolos con otro muro de tapia a intervalos regulares de 4,60 metros apoyados sobre el enlosado» (Gracia, Munilla y Pallarés, 1991: 76). Se dataría en torno al 350 a.C., una época en la que el peso de los factores griego y púnico son difíciles de individualizar en esta zona costera (Ibidem). También cabe recordar en esta comarca que la muralla republicana de Tarragona fue compartimentada en tramos constantes cada $10 \mathrm{~m}$ por muros transversales denominados en su día estribos, los cuales traban al exterior de los paramentos (Serra Vilaró, 1949).

La aportación más llamativa en los últimos años al elenco de esta tipología defensiva proviene del tramo medio del valle del Ebro, zona en la que se mencionan varias ciudades que emplearon esta técnica (Asensio, 1995). En Inestrillas —La Rioja-, identificada con la antigua Contrebia Leukade, el reconocimiento de muros transversales que cada $6 \mathrm{u}$ $8 \mathrm{~m}$ unen los paramentos de la muralla es ya antiguo (Taracena, 1926: 138). Estudios más recientes realzan el carácter aleccionador de la larga y compleja evolución de los sistemas defensivos del poblado, destacando la transformación ocurrida en el periodo celtibérico, al que pertenece la fábrica de cajones, seguramente de la segunda mitad del siglo III a.C. o primeros momentos del II, frente a la muralla de la primera Edad del Hierro que ofrece claras analogías con las de los castros sorianos (Hernández Vera, 1982: 124 y 133).

Otro enclave es La Tijera -Urrea del Jalón, Zaragoza-, cuya muralla se divide en segmentos estancos de 4 a 4,5 m. La recuperación en el relleno de uno de los cajones de un fragmento de cuenco Campaniense B, forma Morel 2.554 b 1, que se fecha a mediados o tercer cuarto del siglo II a.C., aporta un ilustrativo terminus post quem de la construcción de la obra (Asensio, 1995: 303). Igualmente se sospecha que, a pesar de lo menguado de los restos, también el poblado de La Caraza de Valdevallerías - Alcañiz, Teruel- tenía una muralla de cajones, atribuyéndose genéricamente al periodo republicano e imperial (Asensio, 1995: 203-205).

Bajo esta orientación geográfica cobra sentido que la muralla de la ciudad celtibérica de Numancia se organizase en cajones, tal como se desprende de las alusiones de Schulten a los refuerzos de gruesos morrillos que cortan el núcleo de la muralla, luego corroborados por las excavaciones posteriores en varios puntos e interpretados como traveseros cuyo objeto residiría en contener las brechas (González Simancas, 1925-26: 8, 27 y fig.); y todavía son mencionados en recientes descripciones: «a veces este relleno se organiza en torno a una espina longitudinal central constituida por cantos rodados de mayor tamaño y se ve reforzado por muros transversales» (Jimeno, Fernández y Revilla, 1993: 25), debiendo pertenecer a la fortificación de fines del siglo III o principios del II a.C. (Jimeno y Arlegui, 1995: 122). 


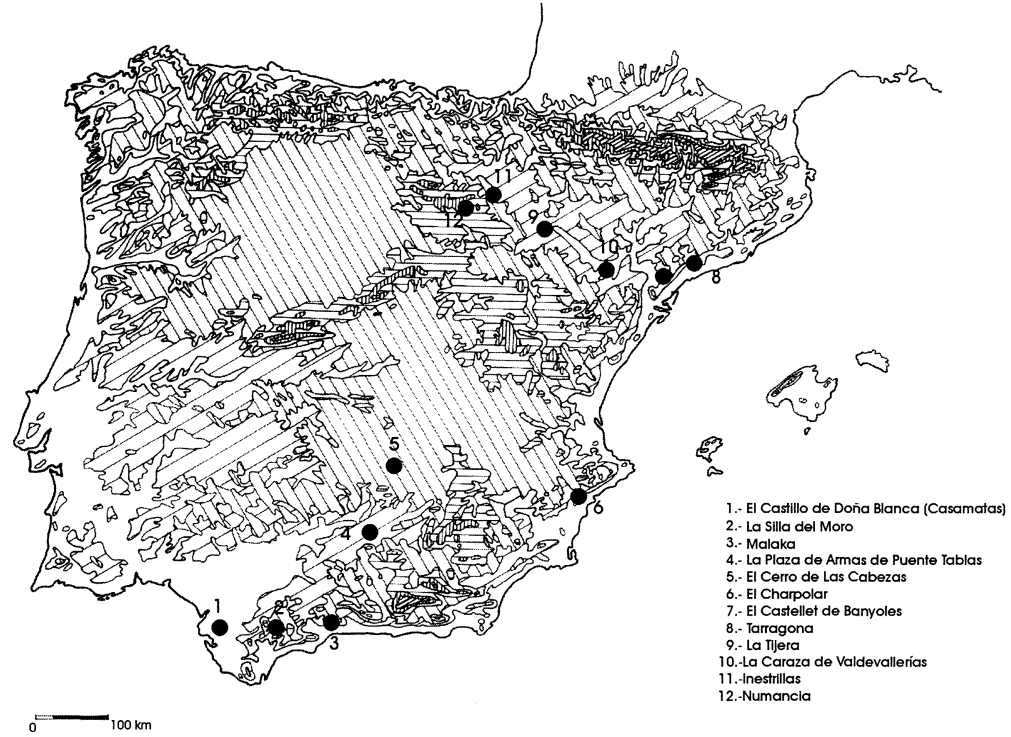

Fig. 8.-Fortificaciones de la Península Ibérica con murallas de cajones.
Ante este panorama no resulta fácil determinar el origen y las causas de la dispersión de las murallas de cajones en la Península. En un primer momento, $\mathrm{P}$. Moret, quien más se ocupó de este tema, las clasificó en la misma categoría que las de casamatas, y las justificó como técnicas fortificativas coloniales que fueron adoptadas por las poblaciones ibéricas, recurriendo entre las primeras a Malaka y al Castillo de Doña Blanca, y para las segundas al Cerro de las Cabezas y al Castellet de Banyoles (Moret, 1991: 267-269). Los desfases cronológico y cultural, suscitados porque los modelos coloniales son fenicio-púnicos mientras los casos ibéricos se propagan en ambientes helenísticos y com-

No queremos terminar este breve repaso sin volver a los castros del centro de la Meseta, cuyas murallas de varios paramentos tanto dieron que hablar y hoy tras los estudios de Moret, al igual que las de algunos castros sorianos, encuentran perfecto acomodo entre las murallas de paramentos múltiples de larga tradición en el Mediodía y Levante peninsular (Moret, 1996: 80 y 230). Y si se traen de nuevo a colación no es para insistir en la falta de vinculación con las moduladas asturianas como más arriba se hizo, sino para buscar algún indicio, leve todavía, que permita establecer cierta relación. Me refiero a la cabecera de un muro aflorante que atraviesa la muralla oriental del segundo recinto de La Mesa de Miranda, de no ser una obra posterior, así como a la junta a que da lugar el paramento externo en el sector occidental de Yecla de Yeltes, compartimentación que es imposible seguir hacia el interior a causa del recubrimiento del terreno. Claro está que de confirmarse esta última, conocida la linealidad de la muralla salmantina, habría de tratarse más de una yuxtaposición ocasional de fábricas quizá derivada del proceso de obra cuyo resultado, eso si, la asemeja a las juntas de los módulos. En este ambiente de inseguridad cabe incluir la alusión a la posible constitución de la muralla del castro de El Raso de Candeleda por paramentos sucesivos adosados para contener las brechas (Fernández Gómez, 1986: 412), aunque tampoco se puntualiza si paralelos o transversales al eje de la fábrica, mención que por su proximidad geográfica nos animó a referir tentativamente los dos ejemplos anteriores que el tiempo habra de definir. probada su ausencia en emplazamientos griegos peninsulares, pudieran ser explicados por el movimiento de mercenarios y comerciantes proclives a importar el modelo en una zona tan sujeta a influencias como la desembocadura del Ebro (Ibidem).

Con posterioridad, probablemente debido al cuesenvejecimiento cronológico del Cerro de las Cabezas, así como a la posible integración del Castillo de matiza su opinión para restar trascendencia poliorcética a esta técnica y, a su vez, separarla de la de casamatas (Moret, 1996: 213). Quizá considerando su aparición en lugares tan desconectados como Cerro de las Cabezas - Ciudad Real-, Silla del Moro Málaga - y Charpolar -Alicante - , repara en que su simplicidad dentro de las técnicas poliorcéticas, algo que siempre tuvo presente, pudo motivar su eclosión al margen de cualquier fenómeno aculturador (Moret, 1996: 213). Mantiene, no obstante, el carácter novedoso de las murallas de cajones y un origen mediterráneo que dio pie a una limitada propagación durante la Edad del Hierro (Ibidem: 84).

Al definirse la muralla del Castillo de Doña Blanca como una obra de casamatas se carece de instalaciones coloniales en la península que hayan inspirado las murallas de cajones, salvo que se admitan como una derivación lejana de aquella, algo no demostrado. Pero al mismo tiempo desaparece también el inconveniente cronológico y cultural a que daba lugar su difusión en tiempos helenísticos. El repaso efectuado a sus manifestaciones peninsulares permitionamiento de los cajones de Banyoles y al ligero Doña Blanca entre la tipología de casamatas, Moret 
te seguir defendiendo ese ámbito para la mayor parte de ellas con lo que podría ser gratuito buscar un centro colonial que justifique un punto de partida.

Los casos más antiguos se materializan en el mediodía, donde, a falta de determinar lo que ocurre en Puente Tablas, han de citarse Silla del Moro y, algo más al norte, el Cerro de Las Cabezas, receptores ambos de fuertes influjos mediterráneos como demuestra la presencia de torres en las dos fortificaciones. Cierta incertidumbre despierta el foco valenciano por su rusticidad y localismo, ¿pero esos rasgos son excluyentes de la adaptación de una técnica foránea?

En la desembocadura del valle del Ebro, el Castellet de Banyoles, a pesar de la problemática que envuelve a sus compartimentaciones, sigue siendo un caso socorrido por su indudable sujeción a un patrón fortificativo de influencia mediterránea emblemática. Además, constituiría un punto de partida para comprender la difusión de la técnica a lo largo de la ruta del Ebro hacia Inestrillas y Numancia, algo que también pudo incidir en Tarraco y en las ciudades aragonesas de época republicana.

\section{HIPÓTESIS SOBRE EL ORIGEN DE LAS MURALLAS DE MÓDULOS EN ASTURIAS}

¿Cómo interpretar en este oscuro balance el grupo asturiano? El problema reside, como corresponde a su localización geográfica, en su aparición en un fondo de saco y en la ausencia hasta ahora de paralelos en las regiones vecinas. El primer intento de solución debe de ser, con todo, intrínseco y pasa por resolver el caos generado sobre la cronología de sus manifestaciones. Los ejemplos más afianzados, aquellos en los que las dataciones radiactivas pueden ser confrontadas con la evolución de estratigrafías largas en el tiempo y con la cultura material, permiten abogar por la datación en el siglo III a.C. en Moriyón, período extensible a la Campa Torres, si es que no debe retrasarse ligeramente hacia finales de ese siglo o principios del II, conforme a la revisión que proponemos de su sistema defensivo. En otros casos, como Llagú y Chao Samartín, las fechas radiactivas tienden a envejecer el horizonte, aunque sin superar el siglo Iv a.C. e incluyendo plenamente el siglo III en su intervalo, con lo que ha de permanecerse a la espera de que el estudio de los materiales y del desarrollo general de las ocupaciones facilite una mayor concreción. Poco se sabe del Castillo de San Martín, pero la posición de la muralla sobre fondos de cabaña que aportaron fíbulas de torrecilla (información de E. Carrocera), apunta a un momento muy avanzado en la segunda Edad del Hierro, cuando no ya romano. Una datación romana me atrevo a sugerir para Castillo Veneiro en consideración a los molinos giratorios encontrados y a su posición en el seno de un destacado sector aurífero explotado por Roma, pero, obviamente, no puede afirmarse con rotundidad. Respecto a San Chuis, al margen de la existencia de ocupaciones antiguas que habrán de ser avaladas con más pruebas, entiendo que una datación radiactiva que tiene una variación a 2 sigmas nada menos que de ¡500 años! y con una confusa vinculación a la muralla, no debe servir para modificar la cronología de ésta, hoy asentada en el periodo imperial según los análisis estratigráficos de F. Jordá y J.L. Maya.

Decíamos antes que el aislamiento de las murallas de módulos asturianas puede invitar a creer en su origen autóctono, idea sustentada en fechas altas, de la primera Edad del Hierro, que tenían en la Campa Torres su principal adalid (Maya y Cuesta, 1995 ; 1999) y que sus investigadores trataron de trasladar al menos a los castros de Llagú (Maya y Mestres, 1998) y San Chuis (Cuesta, Jordá, Maya y Mestres, 1996). Pero con un encuadre de estas murallas a partir del siglo III a.C., a falta de afinar los espectros radiactivos de Llagú y Chao Samartín, se hace mucho más complicado sostener su naturaleza vernácula. En este sentido debiera servir de contraste que las murallas de la primera Edad del Hierro conocidas en la región, bien es cierto que de manera aún incipiente, como las de los castros de Camoca y Olivar en Villaviciosa, no han deparado las consabidas compartimentaciones y su factura ofrece un estilo diferente y tosco.

Con el vacío informativo del espacio circundante a la región, la forma en que esta técnica pudo llegar aquí es una incógnita, pero puede esbozarse una orientación a través de algunos materiales arqueológicos foráneos presentes en castros del centro-oriente de la región. En efecto, si la impronta meseteña de la Edad del Hierro del oriente de Asturias era conocida desde la lejana excavación del castro de Caravia con su puñal de tipo Monte Bernorio y sus fíbulas de torrecilla, caballito, cubo, meseta, etc., las modernas investigaciones han incrementado los testimonios de esa influencia y, así, en una rápida crónica cabe aludir a nuevas fíbulas de torrecilla, simétricas, zoomorfas, Golfo de León, enganches de tahalí, etc. provenientes indistintamente de los poblados de Moriyón y Campa Torres, y muy especialmente deben mencionarse los kalathoi aportados por este último yacimiento. Este lote de piezas, sin contar alguna que otra de incierta procedencia, reclama elocuentes lazos con la zona oriental de la 


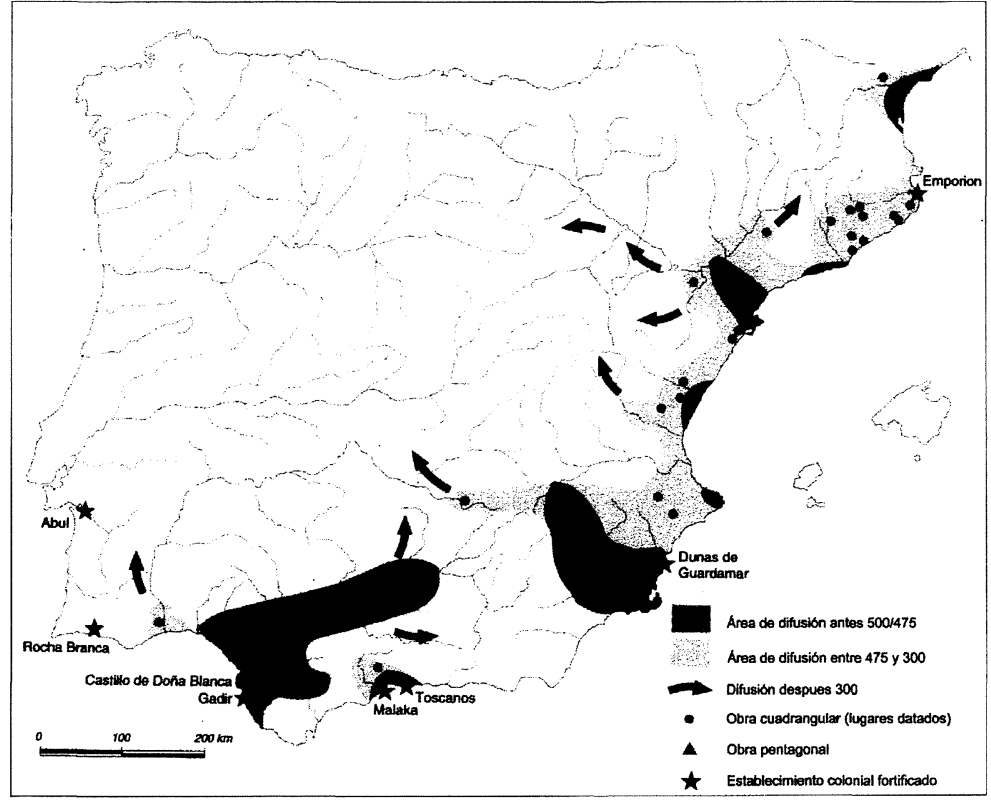

Fig. 9.-Difusión seguida por las obras cuadrangulares y pentagonales en las fortificaciones (a partir de Moret, 1996).

ciones, tamaño, etc. En tierra de los vettones se acepta una paulatina complejidad de los sistemas defensivos como consecuencia de las influencias poliorcéticas del mundo helenístico, y sirve de reflejo para ello confrontar la rústica muralla de Sanchorreja y otros poblados del primer Hierro con los dispositivos defensivos de Las Cogotas o La Mesa de Miranda ya del segundo Hierro (Álvarez-Sanchís, 1999: 164). Esa misma progresión técnica en los sistemas defensivos fue indicada hace ya tiempo para los poblados alaveses (Llanos, 1974: 140), y no es distinta la perspectiva que se diseña en las síntesis sobre la cultura celtibérica, en la que las murallas de cajones surgen novedosamente en la segunda Edad del Hierro (Lorrio, 1997: 79).

A diferencia de lo que ocurre

Meseta norte desde una fase temprana de la segunda Edad del Hierro e invitan a pensar si no podrá ser la vía de llegada de la técnica que nos ocupa. Aún cuando algunas de las murallas compartimentadas de las ciudades del valle del Ebro remiten a la época republicana, otras como la de Inestrillas parecen ser equiparables cronológicamente a las asturianas. Es imposible omitir, a costa de pasar a la cabecera del Duero, los cajones de la muralla indígena de Numancia, tan desmantelada por los acontecimientos posteriores, que se supone de fines del siglo III o principios del il a.C. y que tan cerca está de la riojana. En definitiva, el desenlace difusionista al origen de las murallas asturianas pudiera residir en las fortificaciones del norte de Burgos, Palencia y León de las que tan poco se sabe.

Es un hecho admitido las generalizadas transformaciones técnicas que, como consecuencia de diversos avatares, se producen en las fortificaciones peninsulares grosso modo desde el inicio de la segunda Edad del Hierro. Los cambios acontecidos en la órbita militar y difundidos a través del Mediterráneo favorecieron el incremento de los sistemas defensivos que ahora pasaron a combinar herencias autóctonas con novedosas aportaciones (Balil, 1971: 5).

La evolución de los sistemas defensivos de los poblados protohistóricos es desvelada en numerosas regiones del interior de la Península, observándose una tendencia hacia una mayor elaboración técnica que suele ir acompañada del aumento de manifesta- con las murallas de paramentos múltiples, las murallas de cajones no encuentran antecedentes peninsulares con anterioridad a los primeros tiempos ibéricos y lo hacen siempre en yacimientos sujetos a las influencias coloniales. Basta cotejar el mapa de la dispersión hasta ahora conocida y compararla con la que siguen las torres pentagonales y cuadrangulares (Moret, 1996: 212. Fig. 9), para inferir su claro paralelismo. Esta circunstancia unida al agrupamiento cronológico de las murallas de cajones refuerza el concepto poliorcético de la técnica y que su conocimiento se convirtiese en objeto de difusión. En el caso asturiano, la dificultad para construir las obras defensivas en terrenos llanos, habida cuenta del emplazamiento de las fortificaciones en lugares de altura, pudo ser un acicate en la utilidad de los módulos en un intento de frenar la inestabilidad de las fábricas acelerada por las adversas condiciones climáticas, y ello sin perjuicio del concepto defensivo, poliorcético en su justo término, de la técnica.

\section{ADDENDA}

Ya en prensa este artículo, recordé que Maluquer de Motes se había percatado de las curiosas yuxtaposiciones de paramentos en Yecla la Vieja y Las Merchanas (Maluquer de Motes, J., 1968, «Excavaciones arqueológicas en el castro de 'Las Merchanas' (Lumbrales, Salamanca)», Pyrenae, 4, pp. 101-128). 
Muy recientemente, Jesús Celis me indicó la existencia de módulos en la muralla del castro leonés de El Chano de Peranzanes, datable a caballo del cambio de Era.

Sirva esta nota para reparar la omisión del primero y como agradecimiento al segundo.

\section{BIBLIOGRAFÍA}

ADAM, J.P., 1982, L' architecture militaire grecque, Paris.

Aguayo, P. et alii, 1990, «Excavación arqueológica sistemática en el yacimiento de la Silla del Moro. Primera campaña, 1990», Anuario Arqueológico de Andalucía, II, pp. 245-251.

Álvarez-SANChís, J.R., 1999, Los vettones, Bibliotheca Archeológica Hispana, 1, Real Academia de la Historia, Madrid.

Asensio Esteban, J.A., 1995, La ciudad en el mundo prerromano en Aragón. Caesaraugusta, 70, Zaragoza.

Audouze, F. y Buchsenschutz, O., 1989, Villes, villages et campagnes de l'Europe celtique, Paris.

BALIL, A., 1971, «Casa y urbanismo en la España Antigua. La Segunda Edad del Hierro», Boletín del Seminario de Arte y Arqueología, XXXVII, Universidad de Valladolid, pp. 5-81.

CAmino, J., 1992, «Excavaciones arqueológicas en castros de la ría de Villaviciosa: un poblamiento de la Edad del Hierro», Excavaciones arqueológicas en Asturias, 1987-90, Oviedo, pp. 137144.

- 1995a, «Excavaciones arqueológicas en castros de la ría de Villaviciosa: apuntes para una sistematización de la Edad del Hierro», Excavaciones arqueológicas en Asturias, 1991-1994, Oviedo, pp. 117-126.

- 1995b, Los castros marítimos en Asturias, Fuentes y Estudios de Historia de Asturias, 7, RIDEA, Oviedo.

- 1996, El honor del paisaje. Arqueología y medio rural en Asturias, Oviedo.

- 1999, «Excavaciones arqueológicas en castros de la ría de Villaviciosa. Precisiones cronológicas», Excavaciones arqueológicas en Asturias, 199598, Oviedo, pp. 151-161.

- 2000, «Un yacimiento en la encrucijada. Revisión cronológica de la muralla del castro de Campa Torres (Gijón)», Revista de Arqueología, $\mathrm{n}^{\circ}$ 228, Madrid, pp. 6-12.

CAmino, J. y Viniegra, Y., 1999, «El horizonte cronológico y cultural de la Edad del Hierro en Asturias. El caso de la ría de Villaviciosa», II Con- greso de Arqueología Peninsular, Tomo III, Primer Milenio y Metodología (ed. R. de Balbín y P. Bueno), pp. 239-248.

Carrocera, E., 1994, «Estudio crítico de la cultura castreña asturiana», $1^{\circ}$ Congresso de Arqueología Peninsular, Trabalhos de Antropologia e Etnologia, XXXIV, fasc. 3-4, Porto, pp. 213-221.

Carrocera, E. y Camino, J., 1996, «La Edad del Hierro en el territorio histórico de los ástures o la realidad de un espacio administrativo romano», Los finisterres atlánticos en la Antigüedad. Época prerromana y romana, Ayuntamiento de Gijón, pp. 57-60.

Cuesta, F., Jordá, J., Maya, J.L. y Mestres, J., 1996, «Radiocarbono y cronología de los castros asturianos», Zephyrus, 49, Salamanca, pp. 225-270.

FERnÁNDEZ GómEz, F., 1986, Excavaciones arqueológicas en El Raso de Candeleda, 2 vol., Institución «Gran Duque de Alba», Ávila.

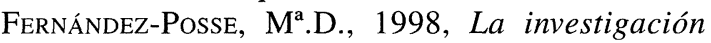
protohistórica en la Meseta y Galicia, Arqueología Prehistórica, 1, Madrid.

GonzÁlez Simancas, M., 1925-26, Excavaciones en las fortificaciones de Numancia, Junta Superior de Excavaciones y Antigüedades, 74, Madrid.

Gracia, F.; Munilla, G. y Pallarés, R., 1991, «Estructuración del poblamiento y sistemas defensivos en el área de la desembocadura del Ebro. Dos casos de estudio: La Moleta del Remei (Alcanar) y el Castellet de Banyoles (Tivissa)», Fortificacions. La problemática de l'Iberic Ple: (segles IV-III a.C.), Manresa, pp. 67-77.

Gusi, F.; DíAz, M.A. y Oliver, A., 1991, «Modelos de fortificación ibérica en el norte del país valenciano», Fortificacions. La problemática de l'Iberic Ple: (segles IV-III a.C.), Manresa, pp. 79102.

HERNÁNDEZ Vera, J.A., 1982, Las ruinas de Inestrillas. Estudio arqueológico. Aguilar del Río Alha$m a$, La Rioja.

Jimeno, A.; Fernández, J.J. y Revilla, Mª.L., 1993, Numancia. Guía del yacimiento, Soria.

Jimeno, A. y ARLEGUI, M., 1995, «El poblamiento en el alto Duero», Poblamiento celtibérico. III Simposio sobre los celtíberos (coor. F. Burillo), Institución «Fernando el Católico», Zaragoza, pp. 93-126.

JoRdÁ CERDÁ, F., 1984, «Notas sobre la cultura castreña del noroeste peninsular», Memorias de Historia Antigua, VI, Universidad de Oviedo, pp. 7-14.

LAWrence, A.W., 1979, Greek Aims in fortification, Oxford.

LLANOS, A., 1974, «Urbanismo y arquitectura en po- 
blados alaveses de la Edad del Hierro», Estudios de arqueología alavesa, VI, Vitoria, pp. 101-146.

Llobregat, A., 1972, La Contestania Ibérica.

LÓPEZ, L.F.; ÁlvAREZ, Y. y LóPEZ, M.A., 1999, «Excavación en el castro de Llagú, Latores (Oviedo 1998). Avance de los resultados», Excavaciones arqueológicas en Asturias, 1995-98, Oviedo, pp. 237-251.

Lorrio, A.J., 1997, Los Celtíberos, Complutum, 7, Madrid.

Martín Valls, R., 1985, «Segunda Edad del Hierro. Las culturas prerromanas», La prehistoria del valle del Duero. Historia de Castilla y León, 1, pp. 104-131.

MAYA, J.L., 1983, «La cultura castreña asturiana: de los orígenes a la romanización», Indigenismo y romanización en el Conventus Asturum, pp. $11-44$.

— 1983-84, «Hábitat y cronología de la cultura castreña en Asturias», Portugalia, III-IV, Porto, pp. 175-198.

- 1988, La cultura material de los castros asturianos, Estudios de la Antigüedad, 4/5, 1988.

- 1989, Los castros en Asturias, Biblioteca Histórica Asturiana, 21.

MAYA, J.L. y CuEstA, F., 1992a, «Excavaciones en la Campa Torres (1986-1990)», Excavaciones arqueológicas en Asturias 1987-1990, Oviedo, pp. 145-152.

- 1992b, «El castro de la Campa Torres», Los orígenes de Gijón (ed. M. Fernández Miranda), Gijón, pp. 37-52.

- 1995, «Estratigrafía e interpretación histórica de la Campa Torres (1991-1994)», Excavaciones Arqueológicas en Asturias 1991-1994, Oviedo, pp. 105-116.

- 1999, «Cronoestratigrafía de la Campa Torres, Gijón. (1995-1998)», Excavaciones arqueológicas en Asturias, 1995-98, Oviedo, pp. 125135.

MAYA, J.L. y Mestres, 1998, «Dataciones prerroma- nas del Castiellu de Llagú (Latores, Oviedo)», Revista de Arqueología, n 195, Madrid, pp. 6-11.

Moret, P., 1991, «Facteurs indigènes et exogènes dans l' évolution de l' architecture défensive ibérique», Fortificacions. La problemàtica de l'ibèric ple: (segles IV-III a.C.), Manresa, pp. 265-271.

- 1996, Les Fortifications Ibériques. De la fin de l' Age du Bronce à la conquête romaine, Collection de la Casa de Velazquez, 56.

Orejas, A. y SÁnchez-Palencia, F.J., 1999, «Arqueología de la conquista del noroeste de la Península Ibérica», II Congreso de Arqueología Peninsular, Tomo IV, Arqueología Romana y Medieval, pp. 23-37.

Recio Ruiz, A., 1988, «Consideraciones acerca del urbanismo de Malaka fenicio-púnica», Mainake, 10, pp. $75-82$.

Ruiz, A.; Molinos, M. y Choclán, C., 1991, «Fortificaciones ibéricas en la alta Andalucía», Fortificacions. La problemàtica de l'ibèric ple: (segles IV-III a.C.), Manresa, pp. 109-126.

Ruiz MatA, D., 1986, «Informe sobre las excavaciones sistemáticas realizadas en el yacimiento del Castillo de Doña Blanca (Puerto de Santa María, Cádiz)», Anuario arqueológico de Andalucía, pp. $360-365$.

Serra Vilaró, J., 1949, «La muralla romana de Tarragona», Archivo Español de Arqueología, 22, Madrid, pp. 221-236.

Taracena, B., 1926, «Noticia de un despoblado junto a Cervera del Río Alhama», Archivo Es-pañol de Arte y Arqueología, Madrid, pp. 137-142.

Vélez, J. y PÉREZ, J.J., 1987, «El yacimiento protohistórico del Cerro de las Cabezas (Valdepeñas, Ciudad Real)», Oretum, III, pp. 167-196.

Villa VAldÉs, A., 1999, «Castro del Chao Samartín (Grandas de Salime): tres años de investigación arqueológica (1995-1998)», Excavaciones arqueológicas en Asturias, 1995-98, Oviedo, pp. 111-123.

WINTER, F.E., 1971, Greek fortifications, Oxford. 